\title{
Patterns of anopheline feeding/resting behaviour and Plasmodium infections in North Cameroon, 2011-2014: implications for malaria control
}

Wolfgang Eyisap Ekoko ${ }^{1,2}$, Parfait Awono-Ambene ${ }^{1}$, Jude Bigoga ${ }^{3}$, Stanislas Mandeng ${ }^{1,4}$, Michael Piameu ${ }^{1,5}$, Narcisse Nvondo ${ }^{4}$, Jean-Claude Toto ${ }^{1}$, Philippe Nwane ${ }^{1}$, Salomon Patchoke ${ }^{6}$, Lili Ranaise Mbakop ${ }^{1,4}$, Jerome Achille Binyang ${ }^{1,4}$, Martin Donelly ${ }^{7}$, Immo Kleinschmidtt ${ }^{8,9}$, Tessa Knox ${ }^{10}$, Arthur Mbida Mbida ${ }^{2}$, Alain Dongmo ${ }^{2}$, Etienne Fondjo ${ }^{6}$, Abraham Mnzava ${ }^{10,11}$ and Josiane Etang ${ }^{1,12,13^{*}}$ (1)

\begin{abstract}
Background: Effective malaria control relies on evidence-based interventions. Anopheline behaviour and Plasmodium infections were investigated in North Cameroon, following long-lasting insecticidal net (LLIN) distribution in 2010.

Methods: During four consecutive years from 2011 to 2014, adult mosquitoes were collected indoors, outdoors and in exit traps across 38 locations in the Garoua, Pitoa and Mayo-Oulo health districts. Anophelines were morphologically and molecularly identified, then analysed for blood meal origins and Plasmodium falciparum circumsporozoite protein (Pf-CSP). Blood from children under 5 years-old using LLINs was examined for Plasmodium infections.

Results: Overall, 9376 anophelines belonging to 14 species/sibling species were recorded. Anopheles gambiae (s.l.) [An. arabiensis (73.3\%), An. coluzzii (17.6\%) and An. gambiae (s.s.) (9.1\%)] was predominant (72\%), followed by An. funestus (s.l.) (20.5\%) and An. rufipes (6.5\%). The recorded blood meals were mainly from humans (28\%), cattle (15.6\%) and sheep (11.6\%) or mixed (45\%). Pf-CSP rates were higher indoors (3.2-5.4\%) versus outdoors (0.8-2.0\%), and increased yearly $\left(X^{2}<18, d f=10, P<0.03\right)$. Malaria prevalence in children under 5 years-old, in households using LLINs was $30 \%$ (924/3088).
\end{abstract}

Conclusions: The present study revealed the variability of malaria vector resting and feeding behaviour, and the persistence of Plasmodium infections regardless the use of LLINs. Supplementary interventions to LLINs are therefore needed to sustain malaria prevention in North Cameroon.

Keywords: Mosquitoes, Alternative hosts, Long-lasting insecticidal nets, Vector behaviour, Malaria infections, North Cameroon

\footnotetext{
*Correspondence: josyet2@gmail.com

${ }^{1}$ Institut de Recherche de Yaoundé (IRY), Organisation de Coordination pour la lutte Contre les Endémies en Afrique Centrale (OCEAC), P.O. Box 288, Yaoundé, Cameroon

Full list of author information is available at the end of the article
} 


\section{Background}

Unprecedented progress has been recorded in malaria control, especially in Africa where a $42 \%$ reduction in case incidence and a $66 \%$ decline in the mortality rate occurred between 2000 and 2016 [1]. However, 200 million cases were recorded in the African Region in 2017, accounting for $92 \%$ of the total case estimates in the world [1].

Approximately 150 different species of Anopheles mosquito have been described in sub-Saharan Africa (SSA); around 20 are primary or secondary malaria vectors [2]. The exceptionally high malaria transmission rates in SSA are in large part ascribed to the constant presence of efficient and competent vectors, especially those belonging to the Anopheles gambiae complex and the An. funestus group. The key elements that make these species highly efficient malaria vectors are anthropophagic and anthropophilic behaviour, i.e. a preference for humans as a source of blood, combined with indoor resting habits (endophily), and exploitation of breeding habitats created by human activities [3-5]. Knowledge of these vector innate feeding preferences and resting habits when combined with data on host availability/accessibility accurately predicts the intensity of malaria transmission [6]. Therefore, understanding how this propensity of malaria mosquitoes to feed on and live amongst humans, changes in response to anti-vector interventions is important for sustaining vector control. For instance, in South Africa, insecticide residual spraying (IRS) in houses was reported to significantly reduce the proportion of An. arabiensis that fed indoors on humans [7]. In this case, the IRS serves to decrease host availability and may either favour alternative innate host preferences in sections of the vector population or induce a "phenotypic plasticity" defined as the modification of host selection without changes in innate (genetic) host preference [8]. In the absence of insecticide resistance, the lack of host-selection phenotypic plasticity in human biting species may cause them to enter the houses and thus increases their likelihood of being killed. Conversely, mosquitoes that do not enter houses will have a selective survival advantage and the intervention may have little effect, especially if these mosquitoes are opportunistic, resistant to insecticides or exhibit plasticity in host selection.

The major malaria vectors in Africa exhibit differential abilities to adapt in widely varying environmental conditions, enabling their survival [4]. For instance, An. gambiae is known to exhibit a high preference for human hosts whereas An. arabiensis is regarded as more opportunistic [9-12]. However, both species, as well as their sibling species An. coluzzii and species of the An. funestus group, have been reported to rapidly develop pyrethroid resistance [13], which renders malaria vector control very complex. To design better vector control and disease prevention measures, it is essential to characterize the behavioural patterns of vector populations over the time and in a range of environmental conditions, especially in the context of pyrethroid resistance among sibling taxonomic units. Such approach would probably be more appropriate than tailoring the interventions according to data on the whole group or the whole complex of vector species.

In Cameroon, the most efficient malaria vector species belong to the An. gambiae complex [An. gambiae (s.s.), An. coluzzii and An. arabiensis], followed by An. funestus, An. nili and An. moucheti groups. Species such as An. paludis, An. pharoensis, An. hankocki and An. rufipes play secondary roles in malaria transmission [14-20]. Furthermore, pyrethroid resistance is widespread in the species of the An. gambiae complex [21-25] and deltamethrin resistance was more recently reported in An. rufipes from the North Region [26]. The number of malaria cases in Cameroon was estimated at 1.2 million in 2013, the majority of which were due to Plasmodium falciparum [27]. Efforts to curb malaria based on widespread use of long-lasting insecticidal nets (LLINs) alongside intensification of case management led to a significant reduction of the prevalence in the general population from $46.3 \%$ in 2008 to $17.6 \%$ in 2017 [27, 28]. Insecticide treated nets (ITNs) act as physical and chemical barriers, preventing access by vector mosquitoes to human hosts, and reducing subsequent blood-feeding and Plasmodium parasite transmission. In order to inform vector control strategies and to identify any factors that may compromise the impact of the interventions, there is a need for a close monitoring of vector populations and parasite transmission. Key entomological indicators to monitor include vector abundance, resting/feeding behaviour and susceptibility to the insecticides used in ITNs or IRS. However in Cameroon, while the status of malaria vector resistance is well known, to date, data on their resting and feeding behaviour in the context of wide LLIN use is scarce. The present report presents data from four cross sectional surveys on malaria vector behaviour conducted yearly from 2011 to 2014 and a cross sectional survey on Plasmodium infections in North Cameroon (2013). This study is part of a multi-country project to assess the impact of insecticide resistance on the effectiveness of LLINs or IRS interventions [29].

\section{Methods}

\section{Study sites and environmental landscapes}

The study was conducted in 38 clusters (defined as villages or groups of hamlets with no less than 500 houses) distributed across 3 health districts (HD), namely 
Garoua, $\left(9^{\circ} 30^{\prime} \mathrm{N}, 13^{\circ} 40^{\prime} \mathrm{E}\right)$, Pitoa $\left(9^{\circ} 21^{\prime} \mathrm{N}, 13^{\circ} 31^{\prime} \mathrm{E}\right)$ and Mayo Oulo $\left(9^{\circ} 46^{\prime} \mathrm{N}, 13^{\circ} 44^{\prime} \mathrm{E}\right)$.

The three study HDs lie within the Soudanian climate domain with $700-1000 \mathrm{~mm}$ of annual rainfall with 3 months of rains (July to October) and 9 months of dry season (November to June). The average temperature in this region is $35 \pm 5{ }^{\circ} \mathrm{C}$. The region contains $1,227,000$ inhabitants and makes up $65,576 \mathrm{~km}^{2}$, with $12-25$ people per $\mathrm{km}^{2}$ in Mayo Oulo, 25-50 people per $\mathrm{km}^{2}$ in Pitoa and $50-100$ people per $\mathrm{km}^{2}$ in Garoua. The region is strewn with rivers and the river valleys are adequate rice growing areas thus they constitute excellent breeding sites for mosquitoes. Anopheles gambiae (s.l.) and An. funestus group are the main malaria vectors in this area.

\section{Mosquito collection}

The study began in November 2011, 18 months after the launch of a LLIN mass distribution campaign in North Cameroon in June 2010. Yearly cross-sectional entomological surveys were conducted during the high transmission seasons between September and November for four consecutive years from 2011 to 2014. To monitor the effect of LLINs on local mosquito populations, only houses that possessed LLINs were selected for mosquito collection, and the same houses were visited each year. Adult mosquitoes were collected across $380(38 \times 10)$ houses randomly chosen in 38 study clusters, using 3 conventional sampling methods: window exit traps (WETs), outdoor clay-pots (OCPs) as outdoor shelters and pyrethrum spray catches (PSCs) [30].

Ten WETs (one per sleeping bedroom window) were set up on windows between 5:00 and 6:00 pm and then checked the next day between 07:00 and 09:00 am for 2 consecutive nights.

For outdoor collection, three 25-30 l OCPs containing 5-10 litres of water were placed in each of 3 selected compounds among those used for WETs (i.e. 9 pots per cluster). The pots were placed at $6: 00 \mathrm{pm}$, preferably at the back of the house close to a bedroom and away from areas with a lot of human activities to avoid disturbing resting mosquitoes. Mosquitoes resting in the pots were collected the next day between 7:00 and 9:00 am for two successive days using mouth aspirators.

PSCs were performed between 6:00 and 9:00 am in all rooms of the 380 study houses once the WET and OCP collections were completed. White sheets were laid on the floor and over the furniture. Then all windows and doors were shut and rooms were sprayed with pyrethrum or pyrethroid based aerosols. The houses were then closed for 10-15 min to knock down the mosquitoes resting indoors. Mosquitoes that fell on the sheets were collected using forceps.
Mosquito samples from the three collection methods were kept separately for subsequent analysis.

\section{Mosquito processing}

Field collected mosquitoes were morphologically identified using keys for the species of the genus Anopheles $[31,32]$ and classified as fed or unfed, based on abdominal appearance. Each mosquito was then dissected and body parts placed into 3 tubes (head/thorax, abdomen and legs/wings). DNA was extracted from the legs and wings of An. gambiae (s.l.) specimens with CTAB 2\% [33] and used for species identification by means of a PCRRFLP method [34]. All heads/thoraxes of the Anopheles samples were screened for Plasmodium falciparum circumsporozoite protein (CSP) and abdomens of fed specimens checked for blood meal origins using ELISA [35, 36]. Monoclonal antibodies against human, cattle, pig, horse, chicken and sheep blood were used for blood meal ELISA.

\section{Malaria prevalence survey}

A malaria prevalence cross-sectional survey was conducted in each cluster of the three study HDs in October 2013. Data on LLINs ownership and usage were collected and 40-45 households owning LLINs were sampled per cluster for Plasmodium parasite screening in children $0.5-5$ years-old. Children were asked if they had slept under bed nets the previous night and if yes, whether they used the nets regularly or not. Furthermore, from the beginning of the study in 2011 and during the study period, the parents were encouraged by the study team to ensure net usage by their children, and the process was monitored by the community health workers. After informed consent of the parents, malaria diagnosis by rapid diagnostic test (RDT) (SD BIOLINE Malaria Ag Pf/ $\operatorname{Pan}^{(\mathrm{r})}$ 05FK60; Standard Diagnostics Inc., Suwon City, South Korea) was performed by health personnel on the children, following the manufacturer's instructions. Children positive by RDT were treated with artesunateamodiaquine according to the national guidelines. Blood slides and thick blood films were also taken. Microscopy was conducted using 10\% Giemsa stain, and examined after completion of fieldwork by laboratory technicians. A second reading was carried out by a technician at OCEAC Laboratory (Yaoundé, Cameroon) and results were compared; the discrepancies were double checked. All technicians were blinded for RDT results.

\section{Statistical analysis}

The human blood index (HBI) was calculated by summing species blood meals from human only and mixed blood meals between human and animals divided by the total blood meals registered per species. Sporozoite rates 
were calculated for each species, as the proportion of mosquitoes tested positive for ELISA CSP. The Pearson Chi-square test was performed to compare LLIN ownership and use in the three HDs, as well as sporozoite rates between malaria vector species, collection methods and years of collection. A one-way ANOVA was conducted to compare the overall vector densities between indoors, exit and outdoor collection, as well as human blood indices. The Anderson-Darling 3-sample test of null was used to compare average relative densities of the major malaria vectors across the three HDs.

\section{Results}

\section{Malaria vector species and abundance}

Data on anopheline diversity and abundance are presented in Fig. 1. A total of 9376 anopheline specimens belonging to 14 species were collected across the 38 study clusters. The anopheline fauna was more diverse in the Pitoa HD with 12 species recorded, followed by the Garoua HD with 9 species recorded, while only 6 species were identified in samples from the Mayo Oulo HD. An. gambiae (s.l.) was predominant $(72.0 \%, n=6758)$, followed by An. funestus (s.l.) $(20.5 \%, n=1922)$ and An. rufipes $(6.5 \%, n=614)$. All other species represented less than $1 \%$ of the total $(n=82)$.

Among the 6758 An. gambiae (s.l.) collected, 3968 specimens randomly selected for molecular identification revealed three sibling species: An. arabiensis (73.3\%), An. coluzzii (17.6\%) and An. gambiae (9.1\%). While An. coluzzii and An. gambiae were at relatively low proportion across the three HDs (5-12\%), An. arabiensis was the predominant species of the entire fauna from the Mayo Oulo and Pitoa HDs (50-58\%), followed by An. funestus
(15-31\%). In the Garoua HD, An. arabiensis occurred at similar proportions with An. funestus (30-34\%), followed by An. rufipes (18\%).

\section{Long-lasting insecticidal net usage and anopheline density indoors and outdoors}

The proportions of households owning at least one LLIN varied between $60-71 \%$, and the rates of LLINs utilization between $43-54 \%$, with no significant difference from one HD to another $\left(x^{2}<3.38, d f=1, P>0.1\right)$.

A total of 2592 clay pots and 2880 exit traps were used for collection of outdoor and exiting mosquitoes, while 1440 rooms were sprayed for indoor collection; the mean relative vector densities are summarized in Table 1 . In the Pitoa HD, the relative anopheline density (mean \pm SD) was higher indoors (3.75 \pm 0.96 anophelines/room), compared with exit traps and outdoors $(1.47 \pm 1.26$ and $2.19 \pm 1.02$ anophelines/trap, respectively), although the difference was not statistically significant $\left(F_{(2,46)}=4.00\right.$, $P=0.05)$. However, in the Garoua and Mayo Oulo HDs, there were no significant differences between mean relative densities among the different collection methods $\left(F_{(24,70)}<1.67, P>0.2\right)$.

Regarding species distribution as shown in Table 2, there was no significant difference between the relative densities of An. arabiensis, An. coluzzii or An. gambiae (s.s.) caught outdoors, in exit traps or indoors $\left(F_{(26,48)}<1.83, P>0.1\right)$. Conversely, An. funestus (s.l.) was mostly found outdoors compared with indoors and exit traps $\left(F_{(4,20)}>8.56, P<0.01\right)$, suggesting exophilic tendencies. The same tendency was observed in An. rufipes, although the differences were not statically significant.

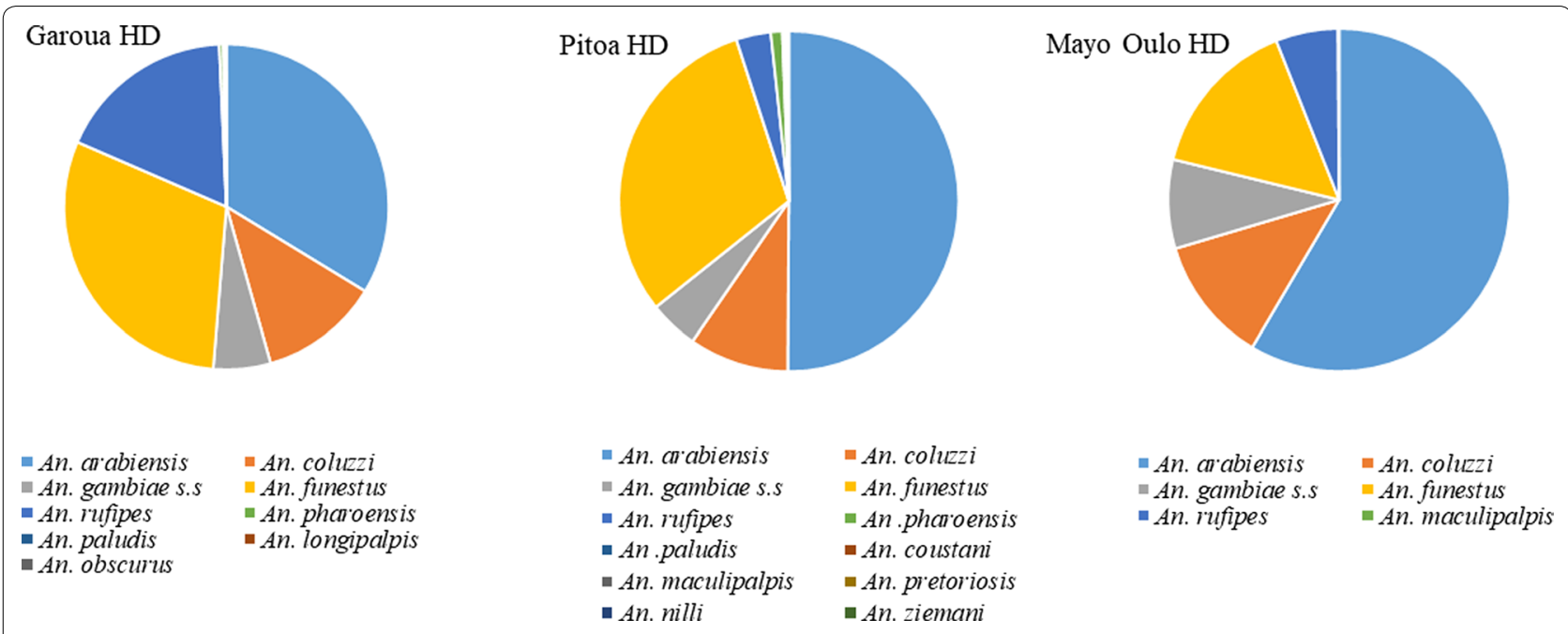

Fig. 1 Species composition of anopheline samples collected in the Garoua, Pitoa and Mayo Oulo Health Districts (HD) from 2011 to 2014 
Table 1 Long-lasting insecticidal net ownership and usage versus anopheline densities indoors, in exit traps and outdoors across the Garoua, Pitoa and Mayo Oulo health districts

\begin{tabular}{|c|c|c|c|c|c|c|c|c|}
\hline Health district & $\begin{array}{l}\text { LLINs } \\
\text { ownership } \\
\text { (\%) }\end{array}$ & LLINs use (\%) & Collection method & No. of traps & $\begin{array}{l}\text { No. of } \\
\text { Anopheles } \\
\text { caught }\end{array}$ & $\begin{array}{l}\text { Mean no. } \pm \text { SD of } \\
\text { Anopheles/trap }\end{array}$ & F-value & $P$-value \\
\hline \multirow[t]{3}{*}{ Garoua } & \multirow[t]{3}{*}{60.1} & \multirow[t]{3}{*}{42.9} & Outdoors & 1080 & 1307 & $1.21 \pm 1.27$ & \multirow[t]{3}{*}{1.67} & \multirow[t]{3}{*}{0.24} \\
\hline & & & Exit trap & 1200 & 1158 & $0.97 \pm 0.70$ & & \\
\hline & & & Indoors & 600 & 1091 & $1.82 \pm 0.74$ & & \\
\hline \multirow[t]{3}{*}{ Pitoa } & \multirow[t]{3}{*}{68.3} & \multirow[t]{3}{*}{54.5} & Outdoors & 864 & 1889 & $2.19 \pm 1.02$ & \multirow[t]{3}{*}{4.00} & \multirow[t]{3}{*}{0.05} \\
\hline & & & Exit trap & 960 & 1412 & $1.47 \pm 1.26$ & & \\
\hline & & & Indoors & 480 & 1799 & $3.75 \pm 0.96$ & & \\
\hline \multirow[t]{3}{*}{ Mayo Oulo } & \multirow[t]{3}{*}{70.8} & \multirow[t]{3}{*}{53.8} & Outdoors & 648 & 172 & $0.27 \pm 0.30$ & \multirow[t]{3}{*}{0.43} & \multirow[t]{3}{*}{0.56} \\
\hline & & & Exit trap & 720 & 225 & $0.31 \pm 0.38$ & & \\
\hline & & & Indoors & 360 & 325 & $0.90 \pm 0.29$ & & \\
\hline
\end{tabular}

Abbreviations: LLINs ownership (\%), percentage of households owning long-lasting insecticidal nets; LLINs use (\%), percentage of households using long-lasting insecticidal nets; SD, standard deviation; $F$-value (one-way ANOVA); $P$-value: significance at $0.05 \%$

Table 2 Mean relative densities of major malaria vector species per collection method

\begin{tabular}{lllll}
\hline Species & ADE $\pm S D$ & ADI $\pm S D$ & ADO $\pm S D$ & $P$-value \\
\hline An. arabiensis & $0.55 \pm 0.57$ & $0.92 \pm 0.72$ & $0.66 \pm 0.54$ & 0.2090 \\
An. coluzzii & $0.12 \pm 0.13$ & $0.22 \pm 0.18$ & $0.16 \pm 0.14$ & 0.1426 \\
An. gambiae (s.s.) & $0.05 \pm 0.06$ & $0.12 \pm 0.11$ & $0.09 \pm 0.10$ & 0.1980 \\
An. funestus & $0.14 \pm 0.16$ & $0.34 \pm 0.39$ & $0.91 \pm 0.83$ & 0.0034 \\
An.rufipes & $0.18 \pm 0.19$ & $0.11 \pm 0.08$ & $0.34 \pm 0.25$ & 0.0781
\end{tabular}

Abbreviations: $\mathrm{ADE}$, average density in exit trap; $\mathrm{ADI}$, average density indoors $A D O$, average density outdoors; SD, standard deviation

\section{Temporal variations of vector densities}

Densities of An. arabiensis, An. coluzzii, An. gambiae (s.s.) generally increased over the years, either indoors, in exit traps or outdoors in some cases $\left(F_{(3,6)}>8.94, P<0.05\right)$. With $A n$. arabiensis from Pitoa, An. coluzzii from Mayo Oulo and $A n$. gambiae from Garoua, the increase was not linear $\left(F_{(16,37)}<2.17, P>0.1\right)$ (Figs. 2,3$)$. However, no significant temporal variations of vector densities were observed outdoors versus indoors and exit traps, except in Pitoa where $A n$. arabiensis, which was mostly caught

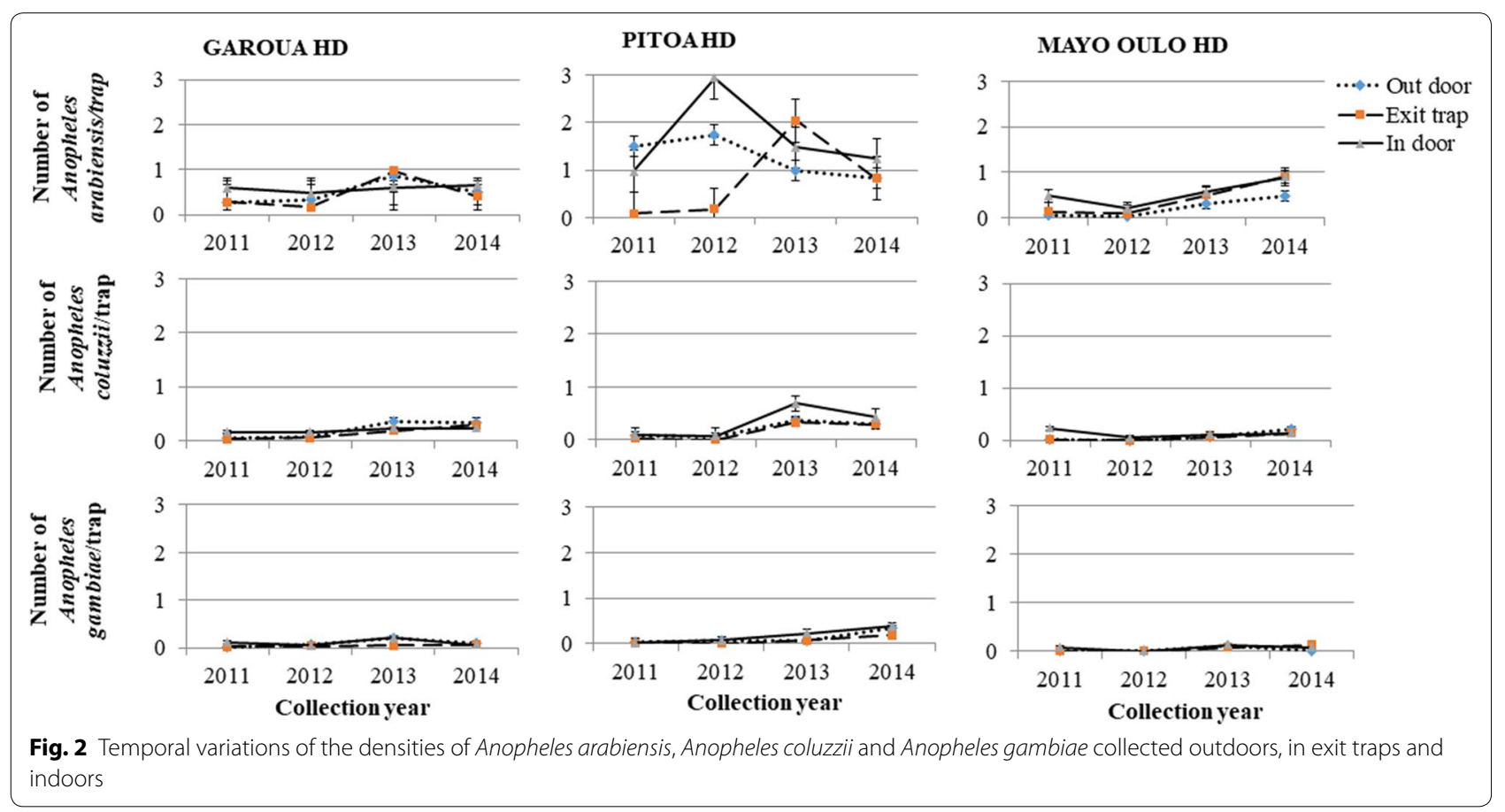




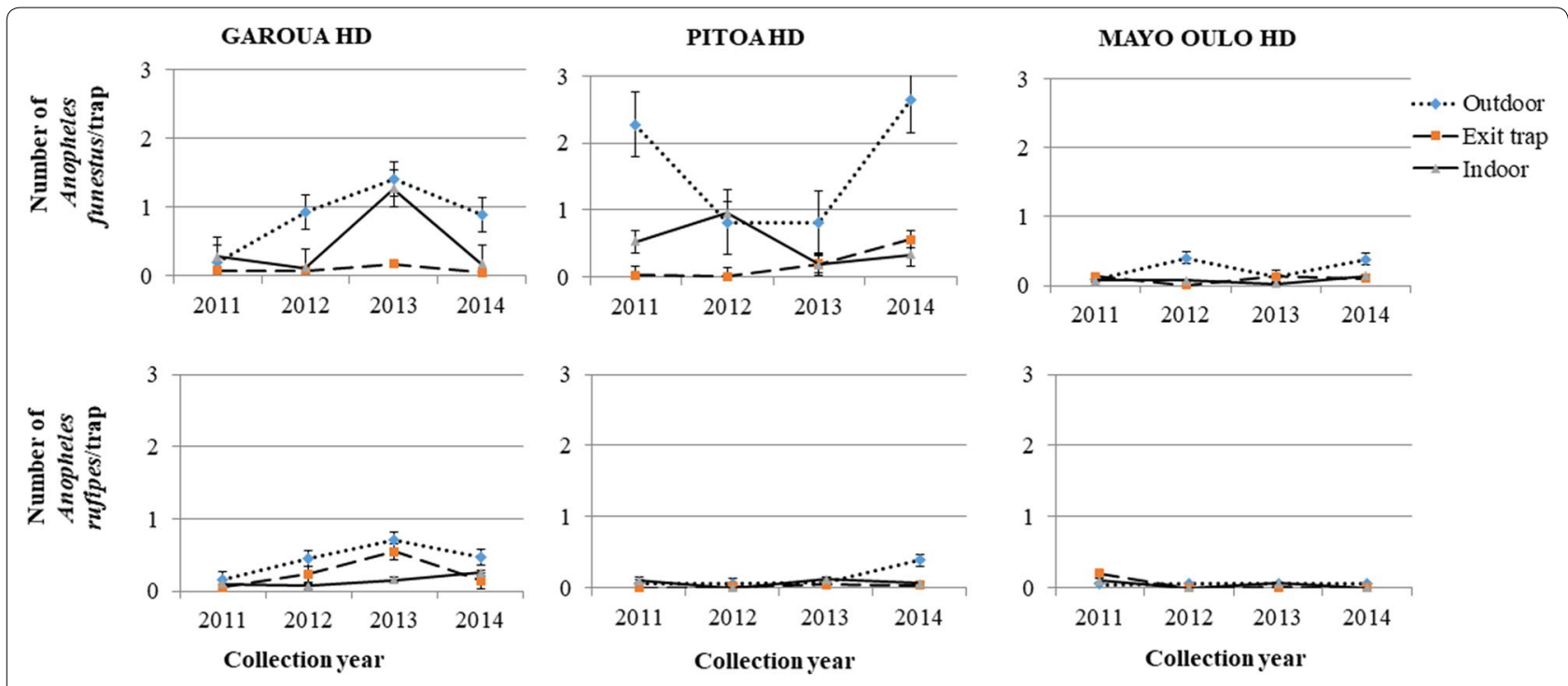

Fig. 3 Temporal variations of the densities of Anopheles funestus and Anopheles rufipes collected outdoors, in exit traps and indoors

indoors than outdoors and exit traps in 2012, was equally caught by the three collection methods in 2014.

Anopheles funestus and An. rufipes were mostly collected outdoors over the course of the study, and no significant variations were recorded in their densities during the four years of the survey $\left(F_{(9,80)}<2.77, P>0.1\right)$.

\section{Blood-feeding indices}

A total of 3014 blood-fed Anopheles corresponding to $32 \%$ of the collected samples were analysed for blood meal origins. Data summarized in Table 3 revealed variable proportions of single-host blood meals and mixed blood meals from one vector species to another and

Table 3 Trophic preference, human and animal blood indices of the five major malaria vectors

\begin{tabular}{|c|c|c|c|c|c|c|c|c|c|}
\hline \multirow[t]{2}{*}{ Health district } & \multirow[t]{2}{*}{ Species } & \multicolumn{7}{|l|}{ Hosts (\%) } & \multirow[t]{2}{*}{$\mathrm{HBI}$} \\
\hline & & Humans & Cattle & Sheep & Pigs & Fowl & Mixed $\mathrm{H} / \mathrm{A}$ & Mixed $A / A$ & \\
\hline \multirow[t]{6}{*}{ Garoua } & An. arabiensis $(n=386)$ & 37.8 & 11.7 & 7.0 & 3.9 & 0.5 & 25.4 & 13.7 & 0.63 \\
\hline & An. coluzzii $(n=159)$ & 44.7 & 6.9 & 3.8 & 3.8 & 1.8 & 28.3 & 10.7 & 0.73 \\
\hline & An. gambiae (s.s.) $(n=73)$ & 61.4 & 5.5 & 5.5 & 2.9 & 0.0 & 11.0 & 13.7 & 0.73 \\
\hline & An. funestus $(n=540)$ & 12.2 & 18.9 & 27.0 & 0.6 & 0.2 & 13.3 & 27.8 & 0.26 \\
\hline & An. rufipes $(n=266)$ & 19.5 & 15.0 & 13.5 & 4.3 & 0.0 & 12.0 & 35.7 & 0.32 \\
\hline & Total $(n=1424)$ & 26.7 & 14.2 & 15.4 & 2.6 & 0.4 & 17.9 & 22.8 & 0.45 \\
\hline \multirow[t]{6}{*}{ Pitoa } & An. arabiensis $(n=665)$ & 29.9 & 14.1 & 10.8 & 1.9 & 0.0 & 23.0 & 20.3 & 0.53 \\
\hline & An. coluzzii $(n=113)$ & 39.8 & 8.0 & 2.7 & 0.9 & 0.0 & 39.8 & 8.8 & 0.80 \\
\hline & An. gambiae (s.s.) $(n=57)$ & 52.6 & 12.3 & 1.6 & 0.0 & 0.0 & 24.7 & 8.8 & 0.77 \\
\hline & An. funestus $(n=357)$ & 11.8 & 7.8 & 9.2 & 1.5 & 0.0 & 35.0 & 34.7 & 0.47 \\
\hline & An. rufipes $(n=48)$ & 10.4 & 12.5 & 4.2 & 4.2 & 0.0 & 35.4 & 33.3 & 0.46 \\
\hline & Total $(n=1240)$ & 25.9 & 11.6 & 9.0 & 1.6 & 0.0 & 28.5 & 23.4 & 0.54 \\
\hline \multirow[t]{6}{*}{ Mayo Oulo } & An. arabiensis $(n=194)$ & 42.3 & 7.2 & 1.0 & 0.0 & 0.0 & 33 & 16.5 & 0.75 \\
\hline & An. coluzzii $(n=51)$ & 51.0 & 0.0 & 0.0 & 0.0 & 0.0 & 41.2 & 7.8 & 0.92 \\
\hline & An. gambiae (s.s.) $(n=30)$ & 60.0 & 0.0 & 0.0 & 0.0 & 0.0 & 33.3 & 6.7 & 0.93 \\
\hline & An. funestus $(n=56)$ & 12.5 & 1.75 & 5.4 & 1.75 & 0.0 & 28.6 & 50 & 0.41 \\
\hline & An. rufipes $(n=19)$ & 15.8 & 21.1 & 10.5 & 0.0 & 0.0 & 21.1 & 31.5 & 0.37 \\
\hline & Total $(n=350)$ & 15.8 & 21.1 & 10.5 & 0.0 & 0.0 & 32.9 & 20.6 & 0.72 \\
\hline
\end{tabular}

Abbreviations: $n$, number of blood meals tested; Mixed H/A, mixed human-animal blood; Mixed A/A, mixed animal-animal blood; $\mathrm{HBl}$, human blood index Note: Numbers in bold refer to HBI higher than 0.50 
from one health district to another. However, the overall proportion of single-host blood meals $(53 \%, n=1603)$ was significantly higher than mixed blood meals (47\%, $n=1411)\left(\chi^{2}=24.46, d f=8, P<0.005\right)$. Single-host blood meals were obtained mainly from humans $(28 \%, n=837)$, cattle $(15.6 \%, n=470)$ and sheep $(11.6 \%, n=350)$. Mixed blood meals were from human/animal (mainly between human/cattle and human/sheep) $(24 \%, n=724)$ and from animal/animal (mainly between cattle/sheep/pig) (23\%, $n=687$ ). Blood from humans, cattle, sheep and pigs was recorded in the five major malaria vector species, whereas blood from fowl was found only in An. colluzzi, An. gambiae and An. funestus.

The three sibling species of the An. gambiae complex showed $30-61 \%$ human blood meals, $11-41 \%$ mixed human/animal and 7-20\% mixed animal/animal meals. The resulting HBIs ranged from 0.53 to 0.93 and were not statistically significant between the three species $\left(F_{(12,16)}=2.89, P=0.13\right)$. Conversely, $10-20 \%$ blood meals of An. funestus and An. rufipes were from human, 1-21\% from animals, $12-35 \%$ from human/animal and $6-50 \%$ from animal/animal. Their HBIs ranged from 0.26 to 0.54 and were significantly lower than those of the three sibling species of the An. gambiae complex $\left(F_{(2,120)}=34.37\right.$, $P<0.005)$.

No significant differences were observed when comparing the mean HBIs of the 5 vector species between the $3 \mathrm{HD}\left(F_{(20,120)}<1.57, P>0.62\right)$.

\section{Plasmodium falciparum circumsporozoite rates}

Overall, 111 specimens among the 5153 analysed tested positive to $P$. falciparum CSP protein, with a mean sporozoite rate of $2.15 \%$. The infected specimens belonged to 7 anopheline species out of the 14 species recorded in the study sites. The three sibling species of the Anopheles gambiae complex had the highest infection rates, corresponding to $4.76 \%$ (14/294), 3.95\% (24/607) and 2.28\% (59/2586) for An. gambiae (s.s.), An. coluzzii and $A n$. arabiensis, respectively. The infection rates were higher in An. gambiae and An. coluzzii, compared with An. arabiensis $\left(\chi^{2}=9.74, d f=2, P=0.007\right)$. For An. funestus and An. rufipes, the infection rates were less than $1 \%$, i.e. $0.77 \%(10 / 1403)$ and $0.71 \%(2 / 258)$, respectively. For An. pharoensis and An. longipalpis, $1 / 10$ and 1/1 analysed specimens were CSP positive, respectively.

The distribution of infection rates among mosquito samples collected indoors, outdoors and exit traps across years of mosquito collection is summarized in Table 4 . In the Garoua and Pitoa HDs, the infection rates were higher in anopheline samples collected indoors (3.22$3.50 \%)$ compared with exit traps $(1.62-2.08 \%)$ and outdoor samples $(0.80-1.30 \%)\left(X^{2}<18, d f=10, P<0.03\right)$. Furthermore in the Pitoa HD, the infection rates significantly increased between 2011 and 2014 from $0.50 \%$ (3/600) to $2.49 \%(25 / 1004)\left(\chi^{2}=16.56, d f=4, P=0.0008\right)$; while in the Garoua HD, two peaks of infections were recorded in $2012(2 / 47,4.25 \%)$ and $2014(25 / 540,4.63 \%)$. In the Mayo Oulo HD, the infection rates remained between $2.13 \%(1 / 47)$ and $4.61 \%(6 / 130)$ across the 4-year study period $\left(\chi^{2}=0.57, d f=3, P=0.90\right)$ and the difference between indoor, exit and outdoor infectivity was not statistically significant $\left(\chi^{2}=2.06, d f=5, P=0.36\right)$

Table 4 Plasmodium falciparum circumsporozoite protein (CSP+) rates in Anopheles samples by method and year of collection

\begin{tabular}{|c|c|c|c|c|c|c|c|c|c|c|c|c|c|}
\hline \multirow[t]{3}{*}{ HD } & \multirow{3}{*}{$\begin{array}{l}\text { Collection } \\
\text { method }\end{array}$} & \multicolumn{8}{|c|}{ Year of collection } & \multirow{2}{*}{\multicolumn{2}{|c|}{ Total }} & \multirow[t]{3}{*}{$x^{2}$} & \multirow[t]{3}{*}{$P$-value } \\
\hline & & \multicolumn{2}{|c|}{2011} & \multicolumn{2}{|c|}{2012} & \multicolumn{2}{|l|}{2013} & \multicolumn{2}{|l|}{2014} & & & & \\
\hline & & $n$ & $\mathrm{CSP}_{+}(\%)$ & $n$ & $\mathrm{CSP}_{+}(\%)$ & $n$ & $\mathrm{CSP}_{+}(\%)$ & $n$ & $\mathrm{CSP}_{+}(\%)$ & $n$ & $\mathrm{CSP}_{+}(\%)$ & & \\
\hline \multirow[t]{4}{*}{ GRA } & OUT & 32 & 0 & 11 & 0 & 479 & 0.83 & 250 & 2.40 & 772 & 1.30 & \multirow[t]{3}{*}{7.77} & \multirow[t]{3}{*}{0.02} \\
\hline & EXIT & 16 & 0 & 9 & 0 & 287 & 1.05 & 121 & 4.96 & 433 & 2.08 & & \\
\hline & IN & 66 & 3.03 & 24 & 8.33 & 370 & 1.35 & 169 & 7.69 & 629 & 3.50 & & \\
\hline & Total & 114 & 1.75 & 47 & 4.25 & 1137 & 1.06 & 540 & 4.63 & 1834 & 2.23 & 22.42 & 0.00005 \\
\hline \multirow[t]{4}{*}{ PIT } & OUT & 407 & 0.25 & 184 & 0 & 181 & 1.10 & 484 & 1.45 & 1256 & 0.80 & \multirow[t]{3}{*}{17.98} & \multirow[t]{3}{*}{0.0001} \\
\hline & EXIT & 14 & 0 & 20 & 0 & 293 & 1.02 & 227 & 2.64 & 554 & 1.62 & & \\
\hline & IN & 179 & 1.12 & 351 & 1.12 & 295 & 5.76 & 293 & 4.09 & 1118 & 3.22 & & \\
\hline & Total & 600 & 0.50 & 555 & 0.72 & 769 & 2.86 & 1004 & 2.49 & 2928 & 1.84 & 16.56 & 0.0008 \\
\hline \multirow[t]{4}{*}{ MYO } & OUT & 3 & 0 & 21 & 0 & 30 & 0 & 44 & 4.55 & 98 & 2.04 & \multirow[t]{3}{*}{2.06} & \multirow[t]{3}{*}{0.36} \\
\hline & EXIT & 10 & 0 & 1 & 0 & 43 & 4.65 & 72 & 2.78 & 126 & 3.17 & & \\
\hline & IN & 34 & 2.94 & 5 & 20.00 & 57 & 7.02 & 71 & 4.22 & 167 & 5.39 & & \\
\hline & Total & 47 & 2.13 & 27 & 3.70 & 130 & 4.61 & 187 & 3.74 & 391 & 3.82 & 0.57 & 0.90 \\
\hline
\end{tabular}




\section{Prevalence of Plasmodium infections in children under 5 years-old}

Data on Plasmodium infections in children under 5 years-old were collected from 31 out of the 38 clusters with entomological data. A total of 3088 children $(\approx 80$ children from 30 households/cluster) were examined for malaria infection using RDT and confirmed using microscopy. The mean age at the recruitment was 27.9 (6-60) months. The number of fever cases (temperature $\geq 37.5{ }^{\circ} \mathrm{C}$ ) was $1494 / 3088(48.4 \%)$ and the number of positive RDT with fever was 958/1494 (64\%). The overall malaria prevalence for the study population was $30 \%$ (924/3088), increasing from Mayo Oulo HD (16\%, $85 / 540)$, to Garoua HD $(23 \%, 340 / 1503)$ and Pitoa HD (48\%, 499/1045) (Fig. 4). A high variability was seen in infection rates among the clusters of the same HD, i.e. $28-70 \%, 6-42 \%$ and $2-25 \%$ in the Pitoa, Garoua and Mayou HDs, respectively. The infections were solely due to P. falciparum.

\section{Discussion}

Entomological and epidemiological monitoring and evaluation of interventions are of great importance for timely and effective response of malaria control programmes. A few studies have been carried out to describe the distribution of malaria vectors and their role in disease transmission in the northern savannah of Cameroon [15, 18-20]. However, little is known about the behavioural response of these vector populations to the wide use of LLINs, while evidence show that successful malaria elimination strategies require interventions that target changing vector behavior [37]. In this study, locally made clay pots were tested and used for the first time to monitor outdoor resting mosquitoes, alongside indoor spray catches for indoor collection and exit traps for collection of mosquitoes escaping from houses through the windows, in areas with 60-70\% LLIN coverage. The used OCPs may have underestimated the relative densities of outdoor resting mosquitoes, because mosquitoes might seek alternative shelters (eaves of huts, canal water pipes, undersides of bridges, cracks and holes in the ground, granaries, etc.) [38-40]. However, the three collection methods yielded consistent samples of mosquitoes for subsequent analysis during a four years longitudinal survey.

Fourteen malaria vector species were identified in study HDs, with three sibling species of the An. gambiae complex, i.e. An. arabiensis, An. coluzzii and An. gambiae (s.s.) being the major vectors, followed by $A n$. funestus (s.l.) and An. rufipes. Species of the An. gambiae complex displayed high HBIs, with increasing relative densities either indoors, across house openings or outdoors; while An. funestus (s.l.) and An. rufipes were mostly found outdoors, with lower HBIs. The predominance of An. arabiensis in the three study HDs located in semiarid areas is consistent with previous observations from the same areas $[18,23,24,41]$ and elsewhere in Africa [42-45]. In the Umbugwe area (now called Magugu) of Northern Tanzania, An. arabiensis has shown a tendency to exit from houses after feeding, a behavioral pattern normally referred to as exophily [46]. Elsewhere in the Kisumu area, Kenya, Highton et al. [47] reported that An. arabiensis showed a tendency to occur outdoors 2.2 times more frequently than indoors, while Joshi et al. [48]

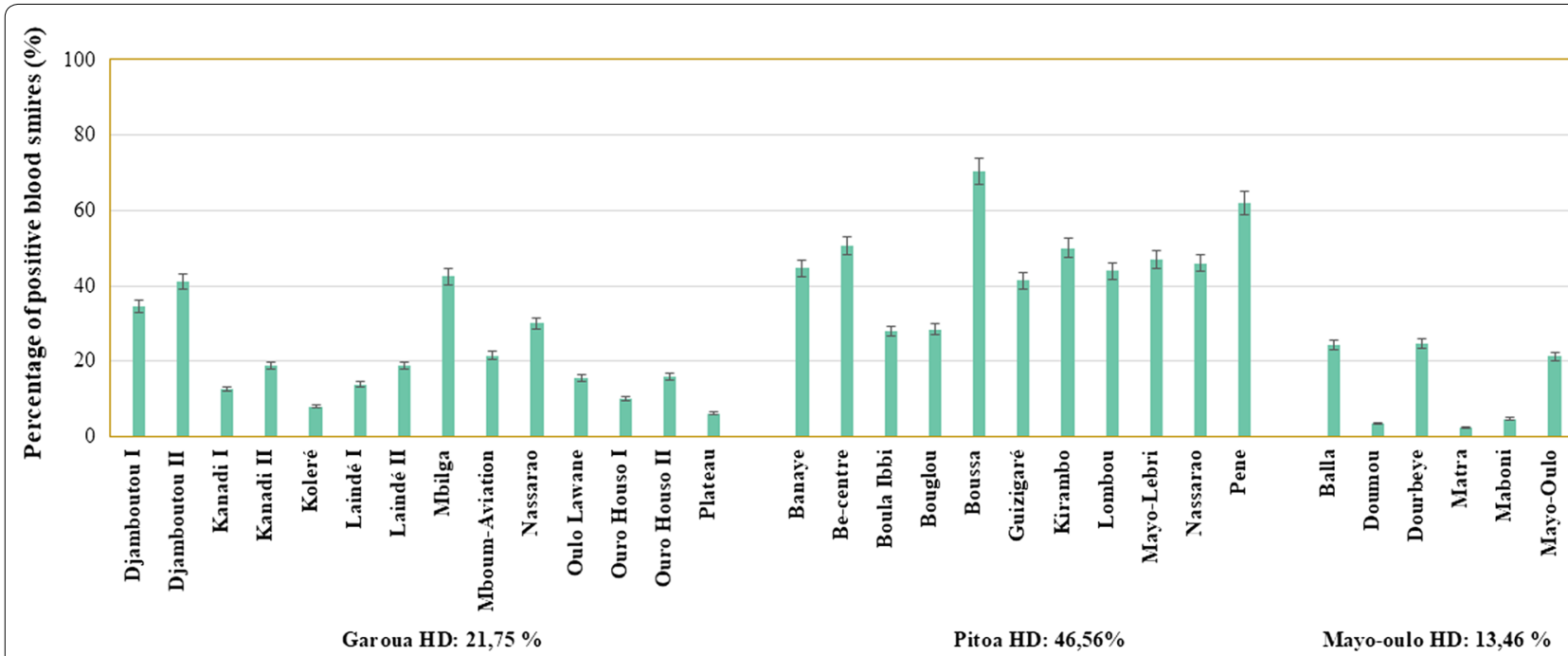

Fig. 4 Malaria prevalence among children under 5 years-old from households using long-lasting insecticidal nets in the Garoua, Pitoa and Mayo Oulo health districts (HD) 
reported 2.8 times. However, the present study found no significant difference between the proportions of $A n$. arabiensis indoors, in exit traps and outdoors. More interestingly, An. gambiae, An. coluzzii and An. rufipes were also largely distributed across the three collection methods; the three species were previously reported to develop resistance to deltamethrin, the same as An. arabiensis in the three study HDs. The synchronous presence of the four species across the collection methods may be related to the heterogeneity of their populations in terms of frequencies of physiological resistance to deltamethrin. Etang et al. [49] previously reported a significant dependence of indoor relative densities of An. arabiensis and $A n$. coluzzii on increasing deltamethrin resistance in the Garoua, Pitoa and Mayo Oulo HDs.

Whereas LLINs were expected to progressively reduce or even eliminate malaria vectors, with subsequent decline of infection rates, the infection rates were higher in mosquitoes collected indoors versus outdoors and increasing from one year to another, suggesting ongoing malaria transmission regardless of the use of LLINs. Moreover, An. funestus (s.l.) was found mostly exophilic and fed on animals. In Burkina Faso, a behavioural divergence was observed between highly anthropophagic and sympatric chromosomal forms of An. funestus known as Folonzo (mosly found indoors) and Kiribina (over-represented outdoors), suggesting that indoor interventions may be less effective against the Kiribina form [50]. Fontenille et al. [51] also found that although very few $A n$. funestus collected indoors in the Manarintsoa area of Madagascar fed on animals, $65.0 \%$ of the exophilic population had fed on bovid blood. The exophilic and zoophilic propensities of An. funestus reported in this study may be related to species or chromosomal composition of sampled populations. Molecular analysis of An. funestus (s.l.) samples from Garoua collected in 2001-2002 revealed three species: An. funestus (s.s.), An. leesoni and An. rivulorum-like from larval collections, versus $93 \%$ An. funestus (s.s.) and 7\% An. leesoni from indoor collections [52]. The biology and vectorial capacity of the three sibling species are highly contrasting. Anopheles funestus (s.s.) is endophilic and anthropophilic, and considered a major vector of human malaria, while An. leesoni and $A n$. rivulorum-like are primarily zoophilic and exophilic, but can also transmit human malaria [2, 53]. Therefore, in the present study, indoor samples carrying human blood may belong to An. funestus (s.s.) species, while exophilic samples carrying animal blood may be of An. leesoni or An. rivulorum-like species. Alternatively, the exophily of An. funestus (s.l.) could also be related to excitorepellency and deterrence of LLINs, assuming that these species were susceptible to deltamethrin. Nevertheless, Menze et al. [54] recently reported multiple insecticide resistance in An. funestus (s.s.) from Gounougou, located $40 \mathrm{~km}$ south-east of Garoua on the right bank of the Benoue River. Further studies are needed to investigate insecticide resistance in the species of the An. funestus group from the Garoua, Pitoa and Mayo Oulo HDs.

Among the seven species found infected with the $P$. falciparum parasite, six had already been incriminated in the study HDs $[15,18-20]$. The seventh species, $A n$. longipalpis, for which the only specimen collected was found infected with $P$. falciparum, needs further investigations, since this species is primarily zoophilic [2] and no strong conclusions could be drawn due to its small sample size. Interestingly, the six major vector species fed on human and animals, mainly cattle and sheep, with a variety of mixed blood meals. Anopheles funestus and An. rufipes obtained a greater proportion of their blood meals from animals. This plasticity of the vector trophic habits may influence the epidemiology of malaria, leading to residual transmission after the main endophilic and endophagic vectors have been reduced by the interventions $[55,56]$. The ongoing malaria transmission in the study HDs was confirmed by high Plasmodium infection rates in children under five years-old using LLINs (30\%), varying from one district to another, and among the clusters of the same HD. These data are consistent with those reported from a nationwide survey conducted after the LLIN distribution campaign in 2011 [57]. The above-mentioned study revealed $60 \%$ LLIN utilization, $36 \%$ malaria prevalence (using RDTs) in children less than six years-old sleeping under LLINs and $66 \%$ prevalence in children not using LLINs. Furthermore, poor housing quality, weaknesses in LLIN coverage (more than two people/net) and low-level education of the heads of the households were identified as the key factors leading to continuous malaria transmission despite LLIN interventions in Cameroon. Such socio-economic and cultural factors are preponderant in most households of the study HDs in North Cameroon, especially in Pitoa where malaria infection rates had increased (47\%), compared with $34 \%$ recorded in 2002 by Etang et al. [58] in children not using ITNs. In addition, the present study underlined that high vector densities, availability of alternative hosts and deltamethrin resistance, worsened by the plasticity in mosquito feeding habits, are key entomological factors limiting the effectiveness of LLINs. The combination of socio-economic and entomological factors among others could therefore explain the increasing malaria infections in the three study HDs. Treatment of livestock with a long-lasting ivermectin formulation, as suggested by Chaccour et al. [59] in Kenya, may be trialled as a complementary tool for malaria vector control in addition to LLINs in North Cameroon. 


\section{Conclusions}

The present study highlights the behavioural plasticity of the major malaria vectors and continuous Plasmodium infection in the presence of LLINs. The high densities of the major vectors, species diversity and ability to feed on domestic animal as alternative hosts are key entomological factors increasing the complexity of vector control via LLINs in North Cameroon. Hence, complementary control measures are needed to sustain malaria control in North Cameroon.

\begin{abstract}
Abbreviations
ANOVA: analysis of variance; CSP: circumsporozoite protein; DNA: deoxyribonucleic acid; ELISA: enzyme-linked immunosorbent assay; HBI: human blood index; HD: health districts; IRS: insecticide residual spraying; LLINs: long-lasting insecticidal nets; MINSANTE: Ministère de la Santé; OCEAC: Organisation de Coordination pour la lutte contre les Endémies en Afrique Centrale; OCP: outdoor clay-pots; PCR-RFLP: polymerase chain reaction-restriction fragment length polymorphism; PSC: pyrethrum spray catches; RDT: rapid diagnostic test; SSA: sub-Saharan Africa; WET: window exit traps; WHO: World Health Organization.
\end{abstract}

\section{Acknowledgements}

We wish to thank Dr Antonio-Nkondjio and Dr Cyrille Ndo for their critical review of the manuscript. Our sincere thanks go to Mr Fesuh Nono Betrand for his contributions in statistical analyses. We also thank Manna, Soulemanou, Andre and Sexy for their support during mosquito sampling and also the local communities for their kind collaboration during field work. We acknowledge Bisseck Camille, Ndoumbe Belisse, Lynda Nouage and Térence Stravensky for their help during laboratory analyses.

\section{Authors' contributions}

JE, PAA, JB and EF conceived and designed the study protocol. WEE, PAA, JE, JB, SM, MP, NN, JCT, PN, SP, LRM and JAB carried out field and laboratory assays. WEE, PAA, JE and PN analysed and interpreted data, and wrote the paper. SM, $M P, L R M, J A B, M D, I K, T K, A B M, A D, E F$ and AM critically reviewed the manuscript. All authors read and approved the final manuscript.

\section{Funding}

Funding was provided by the Bill and Melinda Gates Foundation (grant number: 484991.01). This research forms part of a multi-country study coordinated by the Global Malaria Programme of the World Health Organization. The APC was funded by the European Commission in the framework of DMC-MALVEC project, grant number 688207.

\section{Availability of data and materials}

The data that support the findings of this study are available from the World Health Organization (WHO), but restrictions apply to the availability of these data, which were used under license for the present study and not publicly available. Data are, however, available from the authors upon reasonable request and with the permission of the $\mathrm{WHO}$.

\section{Ethics approval and consent to participate}

Ethical clearance for the study was requested from the National Ethics Committee of Cameroon under the reference number FWA IRB00001954 and approved through the authorization number 102/CNE/SE/09. Informed consent was obtained from heads of households or their representatives and community leaders before access to houses and bedrooms for mosquito collections and blood testing.

\section{Consent for publication}

Not applicable.

\section{Competing interests}

The authors declare that they have no competing interests.

\section{Author details}

${ }^{1}$ Institut de Recherche de Yaoundé (IRY), Organisation de Coordination pour la lutte Contre les Endémies en Afrique Centrale (OCEAC), P.O. Box 288, Yaoundé, Cameroon. ${ }^{2}$ Laboratory of Animal Biology and Physiology, University of Douala, P.O Box 24157, Douala, Cameroon. ${ }^{3}$ National Reference Unit (NRU) for Vector Control, The Biotechnology Center, University of Yaounde I, P.O. Box 3851, Messa, Yaoundé, Cameroon. ${ }^{4}$ Faculty of Sciences, University of Yaounde I, P.O Box 337, Yaoundé, Cameroon. ${ }^{5}$ Ecole des Sciences de la Santé, Université Catholique d'Afrique Centrale, B.P. 1110 Yaoundé, Cameroun. ${ }^{6}$ National Malaria Control Programme, Ministry of Public Health, PO Box 14386, Yaoundé, Cameroon. ${ }^{7}$ Department of Vector Biology, Liverpool School of Tropical Medicine, Pembroke Place, Liverpool L3 5QA, UK. ${ }^{8}$ MRC Tropical Epidemiology Group, Department of Infectious Disease Epidemiology, London School of Hygiene and Tropical Medicine, Keppel Street, London WC1E 7HT, UK. ${ }^{9}$ School of Pathology, Faculty of Health Sciences, University of the Witwatersrand, Johannesburg, South Africa. ${ }^{10} \mathrm{Global}$ Malaria Programme, World Health Organization, Avenue Appia 20, 1211 Geneva, Switzerland. ${ }^{11}$ African Leaders Malaria Alliance, 3 Barack Obama Avenue, Dar es Salaam, Tanzania. ${ }^{12}$ Faculty of Medicine and Pharmaceutical Sciences, University of Douala, P.O. Box 2701, Douala, Cameroon. ${ }^{13}$ Institute for Insect Biotechnology, Justus-Liebig-University Gießen, Winchester Str. 2, 35394 Giessen, Germany.

Received: 9 January 2019 Accepted: 3 June 2019

Published online: 13 June 2019

\section{References}

1. WHO. World malaria report 2018. Geneva: World Health Organization; 2018.

2. Kyalo D, Amratia P, Mundia CW, Mbogo CM, Coetzee M, Snow RW. A geocoded inventory of anophelines in the Afrotropical Region south of the Sahara: 1898-2016. Wellcome Open Res. 2017;2:57.

3. White GB, Rosen P. Comparative studies on sibling species of the Anopheles gambiae Giles complex (Dipt., Culicidae). II. Ecology of species A and $B$ in savanna around Kaduna, Nigeria, during transition from wet to dry season. Bull Entomol Res. 1973;62:613-25.

4. Coluzzi M, Sabatini A, Petrarca V, Di Deco MA. Chromosomal differentiation and adaptation to human environments in the Anopheles gambiae complex. Trans R Soc Trop Med Hyg. 1979;73:483-97.

5. White BJ, Collins FH, Besansky NJ. Evolution of Anopheles gambiae in relation to humans and malaria. Annu Rev Ecol Evol S. 2011;42:111-32.

6. Lehane M. The biology of bloodsucking in insects. 2nd ed. Cambridge: Cambridge University Press; 2005.

7. Sharp LB, le Sueur LD. Behavioural variation of Anopheles arabiensis (Diptera: Culicidae) population in Natal, South Africa. Bull Entomol Res. 1991;81:107-10.

8. Lefèvre T, Gouagna LC, Roch KD, Elguero E, Fontenille D, Renaud F, et al. Beyond nature and nurture: Phenotypic plasticity in blood-feeding behavior of Anopheles gambiae s.s. when humans are not readily accessible. Am J Trop Med Hyg. 2009;81:1023-9.

9. Trung HD, Van Bortel W, Sochantha T, Keokenchanh K, Briët OJT, Coosemans M. Behavioural heterogeneity of Anopheles species in ecologically different localities in Southeast Asia: a challenge for vector control. Trop Med Int Health. 2005;10:251-62.

10. Besansky N, Hill CA, Costantini C. No accounting for taste: host preference in malaria vectors. Trends Parasitol. 2004;20:250-1.

11. Coluzzi M, Sabatini A, della Torre A, Di Deco MA, Petrarca VA. Polytene chromosome analysis of the Anopheles gambiae species complex. Science. 2002;298:1415-8.

12. Day JE. Host-seeking strategies of mosquito disease vectors. J Am Mosq Control Assoc. 2005;21:17-22.

13. WHO. Atlas on trends and current status of insecticide resistance in malaria vectors of the WHO African Region. Geneva: World Health Organization; 2016.

14. Awono-Ambene P, Kengne Simard F, Antonio-Nkondjio C, Fontenille D. Description and bionomics of Anopheles (Cellia) ovengensis (Diptera: 
(ulicidae), a new malaria vector species of the Anopheles nili group from south Cameroon. J Med Entomol. 2004;41:561-8.

15. Cohuet A, Simard F, Wondji CS, Antonio-Nkondjio C, Awono-Ambene P, Fontenille D. High malaria transmission intensity due to Anopheles funestus (Diptera: Culicidae) in a village of savannah-forest transition area in Cameroon. J Med Entomol. 2004;41:901-5.

16. Antonio-Nkondjio C, Kerah CH, Simard F, Awono-Ambene P, et al. Complexity of the malaria vectorial system in Cameroon: contribution of secondary vectors to malaria transmission. J Med Entomol. 2006:43:1215-21.

17. Bigoga DJ, Manga L, Titanji VPK, Coetzee M, Leke RGF. Malaria vectors and transmission dynamics in coastal south-western Cameroon. Malar J. 2007:6:5.

18. Antonio-Nkondjio C, Atangana J, Ndo C, Awono-Ambene P, Fondjo E, Fontenille D, Simard F. Malaria transmission and rice cultivation in Lagdo, northern Cameroon. Trans R Soc Trop Med Hyg. 2008;102:352-9.

19. Atangana J, Bigoga JD, Patchoke S, Ndjemai MN, Tabue RN, Nem TE, et al. Anopheline fauna and malaria transmission in four ecologically distinct zones in Cameroon. Acta Trop. 2010;115:131-6.

20. Tabue RN, Awono-Ambene P, Etang J, Atangana J, Antonio-Nkondjio C, Toto JC, et al. Role of Anopheles (Cellia) rufipes (Gough, 1910) and other local anophelines in human malaria transmission in the northern savannah of Cameroon: a cross-sectional survey. Parasit Vectors. 2017;10:22.

21. Etang J, Manga L, Chandre F, Guillet P, Fondjo E, Mimpfoundi R, Toto JC, Fontenille D. Insecticide susceptibility status of Anopheles gambiae s.I. (Diptera:Culicidae) in the Republic of Cameroon. J Med Entomol. 2003:40:491-7.

22. Etang J, Manga L, Toto JC, Guillet P, Fondjo E, Chandre F. Spectrum of metabolic based resistance to insecticides in Anopheles gambiae s.l. populations from Cameroon. J Vect Ecol. 2007;32:123-33.

23. Chouaïbou M, Etang J, Brevault T, Nwane P, Hinzoumbé CK, Mimpfoundi $\mathrm{R}$, Simard F. Dynamics of insecticide resistance in the malaria vector Anopheles gambiae s.l. from an area of extensive cotton cultivation in Northern Cameroon. Trop Med Int Hlth. 2008;13:476-86.

24. Nwane P, Etang J, Chouaibou M, Toto JC, Kerah-Hinzoumbé C, Mimpfoundi R, et al. Trends in DDT and pyrethroid resistance in Anopheles gambiae s.s. populations from urban and agro-industrial settings in southern Cameroon. BMC Infect Dis. 2009;9:163.

25. Antonio-Nkondjio C, Tene Fossog B, Kopya E, Poumachu Y, Menze Djantio $M, N d o C$, et al. Rapid evolution of pyrethroid resistance prevalence in Anopheles gambiae populations from the cities of Douala and Yaoundé (Cameroon). Malar J. 2015;14:155.

26. Awono-Ambene P, Etang J, Antonio-Nkondjio C, Ndo C, Ekoko Eyisap W, Piameu MC, et al. The bionomics of the malaria vector Anopheles rufipes Gough, 1910 and its susceptibility to deltamethrin insecticide in North Cameroon. Parasit Vectors. 2018;11:253.

27. Kwenti TE, Kwenti TDB, Njunda LA, Latz A, Tufon KA, Nkuo-Akenji T. Identification of the Plasmodium species in clinical samples from children residing in five epidemiological strata of malaria in Cameroon. Trop Med Health. 2017;45:14

28. MINSANTE. Plan stratégique National de lutte contre le paludisme au Cameroun 2014-2018. Yaounde Cameroon: Ministry of Health; 2016.

29. Kleinschmidt I, Mnzava AP, Kafy HT, Mbogo C, Bashir Al, Bigoga J, et al. Design of a study to determine the impact of insecticide resistance on malaria vector control: a multi-country investigation. Malar J. 2015;14:282.

30. Service MW. Mosquito ecology field sampling methods. 2nd ed. London: Elsevier Appl Sci; 1993.

31. Gillies MT, De Meillon BA. The Anophelinae of Africa south of the Sahara (Ethiopian Zoogeographical Region). Pub S Afr Inst Med Res Jburg. 1968;54:131-2.

32. Gillies MT, Coetzee M. A supplement to the Anophelinae of Africa South of the Sahara (Afro-tropical region). Pub S Afr Inst Med Res Jburg. 1987:55:78-143

33. Collins FH, Mendez MA, Razmussen MO, Mehaffey PC, Besansky NJ, Finnerty VA. Ribosomal RNA gene probe differentiates member species of Anopheles gambiae complex. Am J Trop Med Hyg. 1987;37:37-41.

34. Fanello C, Santolamazza F, Torré D. A Simultaneous identification of species and molecular forms of the Anopheles gambiae complex by PCRRFLP. Med Vet Entomol. 2002;16:461-4.
35. Burkot TR, Williams JL, Schneider I. Identification of Plasmodium falciparum-infected mosquitoes by a double antibody enzyme-linked immunosorbent assay. Am J Trop Med Hyg. 1984;33:783-8.

36. Beier JC, Koros JK. Visual assessment of sporozoite and blood meal ELISA samples in malaria field studies. J Med Entomol. 1991;28:805-8.

37. Russell TL, Beebe NW, Cooper RD, Lobo NF, Burkot TR. Successful malaria elimination strategies require interventions that target changing vector behaviours. Malar J. 2013;12:56-61.

38. Muirhead TRC. Mosquito behaviour in relation to malaria transmission and control in the tropics. London: Arnold; 1951. p. 60.

39. Service MW. The ecology of the mosquitoes of the Northern Guinea Savannah of Nigeria. Bull Entomol Res. 1963;54:601-32.

40. Githeko AK, Service MW, Mbogo CM, Atieli FK. Resting behaviour, ecology and genetics of malaria vectors in large scale agricultural areas of western Kenya. Parassitologia. 1996;38:481-9.

41. Chouaibou M, Simard F, Chandre F, Etang J, Darriet F, Hougard JM. Efficacy of bifenthrin-impregnated bed nets against Anopheles funestus and pyrethroid-resistant Anopheles gambiae in North Cameroon. Malar J. 2006;5:77.

42. White GB, Magayuka SA, Boreham PFL. Comparative studies on sibling species of the Anopheles gambiae Giles complex (Diptera: Culicidae): bionomics and vectorial activity of species A and species B at Segera, Tanzania. Bull Entomol Res. 1974;62:215-317.

43. Mosha FW, Petrarca V. Ecological studies on Anopheles gambiae complex sibling species on the Kenya coast. Trans R Soc Trop Med Hyg. 1983;77:344-5.

44. Smith A. Observations on the man-biting habits of some mosquitoes in the South Pare area of Tanganyika. East Africa Med J. 1961;38:246.

45. Mahande A, Mosha F, Mahande J, Kweka E. Feeding and resting behaviour of malaria vector, Anopheles arabiensis with reference to zooprophylaxis. Malar J. 2007;6:100.

46. Onyabe DY, Conn JE. The distribution of two major malaria vectors, Anopheles gambiae and Anopheles arabiensis, in Nigeria. Mem Inst Oswaldo Cruz. 2001;96:1081-4.

47. Highton RB, Bryan JH, Boreham PFL, Chandler JA. Studies on the sibling species Anopheles gambiae Giles and Anopheles arabiensis Patton (Diptera: Culicidae) in the Kisumu area, Kenya. Bull Entomol Res. 1979:69:43-53.

48. Joshi GP, Service MW, Pradhan GD. A survey of species A and B of the Anopheles gambiae Giles complex in the Kisumu area of Kenya prior to insecticidal spraying with OMS-43 (fenitrothion). Ann Trop Med Parasitol. 1975;69:91-104.

49. Etang J, Fesuh Nono B, Awono-Ambene P, Bigoga J, Ekoko Eyisap W, Piameu $\mathrm{M}$, et al. Resting behaviour of deltamethrin resistant malaria vectors in North Cameroon: upshots from a two level ordinary logit model. In: Rodriguez-Morales A, editor. Current topics in malaria. Rijeka, Croatia: InTechOpen; 2016. p. 453-72.

50. Guelbeogo WM, Sagnon NF, Liu F, Besansky NJ, Costantini C. Behavioural divergence of sympatric Anopheles funestus populations in Burkina Faso. Malar J. 2014;13:65.

51. Fontenille D, Lepers JP, Campbell GH, Coluzzi M, Rakotoarivony I, Coulanges P. Malaria transmission and vector biology in Manarintsoa, high plateaux of Madagascar. Am J Trop Med Hyg. 1990;43:107-15.

52. Cohuet A, Simard F, Toto JC, Kengne P, Coetzee M, Fontenille D. Species identification within the Anopheles funestus group of malaria vectors in Cameroon and evidence for a new species. Am J Trop Med Hyg. 2003;69:200-5.

53. Wilkes TJ, Matola YG, Charlwood JD. Anopheles rivulorum, a vector of human malaria in Africa. Med Vet Entomol. 1996;10:108-10.

54. Menze BD, Riveron JM, Ibrahim SS, Irving H, Antonio-Nkondjio C, AwonoAmbene $\mathrm{PH}$, et al. Multiple insecticide resistance in the malaria vector Anopheles funestus from Northern Cameroon is mediated by metabolic resistance alongside potential target site insensitivity mutations. PLoS ONE. 2016;11:e0163261.

55. Durnez L, Coosemans M. Residual transmission of malaria: an old issue for new approaches. In: Manguin S, editor. Anopheles mosquitoes: new insights into malaria. Rijeka, Croatia: InTechOpen; 2013. p. 671-704.

56. Afrane YA, Bonizzoni M, Yan G. Secondary malaria vectors of sub-Saharan Africa: threat to malaria elimination on the continent? In: RodriguezMorales A, editor. Current topics in malaria. Rijeka, Croatia: IntechOpen; 2016. p. 473-90. 
57. Bonnal L, Favard P, Tomen NH. Protection and disease risk: the case of malaria in Cameroon. Insur Manage Risks. 2015;82:98-130.

58. Etang J, Chouaibou M, Toto JC, Faye O, Manga L, Same-Ekobo A, et al. A preliminary test of the protective efficacy of permethrin-treated bed nets in an area of Anopheles gambiae metabolic resistance to pyrethroids in North Cameroon. Trans R Soc Trop Med Hyg. 2007;101:881-4.

59. Chaccour CJ, Nghabi K, Abizanda G, Barrio Al, Aldaz A, Okumu F, et al. Targeting cattle for malaria elimination: marked reduction of Anopheles arabiensis survival for over six months using a slow release ivermectin implant formulation. Parasit Vectors. 2018;11:287.

\section{Publisher's Note}

Springer Nature remains neutral with regard to jurisdictional claims in published maps and institutional affiliations.
Ready to submit your research? Choose BMC and benefit from:

- fast, convenient online submission

- thorough peer review by experienced researchers in your field

- rapid publication on acceptance

- support for research data, including large and complex data types

- gold Open Access which fosters wider collaboration and increased citations

- maximum visibility for your research: over 100M website views per year

At BMC, research is always in progress.

Learn more biomedcentral.com/submissions 